\title{
The Relationship between Nocturia, Sleep Quality and Daytime Energy among Community Dwelling Older Adults
}

\author{
Abeer Ramadan Awade, Demonstrator \\ Gerontological Nursing, Faculty of Nursing, Damanhour University \\ Nagwa Abd El Fattah Ibrahim, Professor \\ Gerontological Nursing, Faculty of Nursing, Alexandria University \\ Maha Mohammed Abd El Moniem, Lecturer \\ Gerontological Nursing, Faculty of Nursing, Alexandria University
}

\begin{abstract}
Nocturia is one of the greatest disruptive lower urinary tract symptoms and among the prime sources of disturbed sleep in the elderly. By splitting the sleep cycle, it adversely influences the quality of sleep and subsequently is associated with daytime exhaustion. Even with the highly disrupting nature of nocturia, geriatric sufferers often do not seek medical attention, viewing it as an expected result of aging or being too ashamed to discuss it. Objective: Determine the relationship between nocturia, sleep quality and day time energy among community dwelling older adults. Setting: Seven outpatient clinics in the main university hospital in Alexandria, Egypt. Subjects: A convenience sample of 130 geriatric patients with nocturia. Tools: Socio-demographic and clinical data structured interview schedule of geriatric patients, sleep quality and day time energy of geriatric patients with nocturia structured interview schedule. Results: 46.9 and $31.5 \%$ of elders with nocturia had fairly good and poor $S Q$ respectively, poor and moderate level of day time energy represented 39.2 and $33.1 \%$ respectively. A positive statistical significant relation was observed between sleep quality and day time energy of geriatric patients with nocturia. Frequency and duration of nocturia was significantly associated with sleep quality and day time energy. Conclusion: The more the number of nocturnal voids the poorer the sleep quality and the lower the daytime energy. Recommendations: Health care providers should regularly assess those patients at-risk for nocturia and use it as a screen test for predicting other serious medical disorders.
\end{abstract}

Keywords: Nocturia; Sleep quality; Day time energy; Geriatric patient.

\section{Introduction}

Nocturia is one of the greatest disruptive lower urinary tract symptoms and among the prime sources of disturbed sleep in the elderly ${ }^{(1,2)}$. More than $70 \%$ of people aged 70 years and over suffer from nocturia. In the USA, the prevalence of nocturia of more than two voids per night was $58.5 \%{ }^{(3,4)}$. In Egypt the total number of people with one or more void per night was $63.5 \%{ }^{(5)}$. According to the International Continence Society (ICS), nocturia is recognized as "the complaint that an individual has to wake one or more times to void, each void is preceded and followed by sleep" $^{\prime(6)}$. Advanced age is accompanied by many physiological changes in the urinary system predisposing older people to nocturia. Among these changes are diminished bladder capacity, involuntary bladder contractions, increased nocturnal urine production and decreased bladder and pelvic floor muscle tone ${ }^{(7,8)}$. In addition to physiological changes, nocturia in older adults is associated with various conditions and circumstances that influence antidiuretic hormone secretion (ADH) including, endocrine disorders, heart failure, renal insufficiency, obstructive sleep apnea, benign prostatic hyperplasia and medication $^{(9,10)}$. Regardless of the reason of nocturia, latest visions have led to the confirmation that nocturia has a multifactorial pathogenesis and should be considered as a separate clinical disorder 
rather than being a symptom of lower urinary tract (LUT) dysfunction ${ }^{(11)}$. In addition to, the age associated variation in circadian rhythms and higher co-morbidities, nocturia might demonstrate a particular risk for the sleep quality of older adults. By splitting the sleep cycle, it leads to diminished vitality which in turn affects daytime activity and mental functioning and vigilance. Frequent nocturnal voids increases fatigue and duplicate the danger of falls and fractures at night ${ }^{(12-15)}$. Additionally, nocturia has been publicized to be an independent risk factor of mortality among seniors ${ }^{(16)}$. The deleterious impact of nocturia is extended to include sleep disturbance of spouses of nocturia sufferers due to their partners' night-time awakenings to $\operatorname{void}^{(17)}$.

Even with the highly disrupting nature of nocturia, it is inadequately studied and frequently ignored by health care providers as a cause of bothered sleep and decreased day time energy in the older population ${ }^{(18)}$. Moreover, geriatric sufferers themselves often do not seek medical attention, considering it as an expected result of aging process or being too ashamed to discuss it. So, it is noteworthy for the gerontological nurse and other health care providers caring for older patients to identify and assess geriatric patients with nocturia and to evaluate its relationship with sleep quality (SQ) and day time energy in order to recruit prompt and appropriate nursing interventions that may prevent further ramifications and enhance quality of all life domains.

\section{Aim of the Study}

This study aims to determine the relationship between nocturia, sleep quality and day time energy among community dwelling older adults.

\section{Research Question}

What is the relationship between nocturia, sleep quality and day time energy among community dwelling older adults?

\section{Materials and Method}

\section{Materials}

Design: A descriptive correlational research design was followed in this study.

Setting: The study was conducted in seven outpatient clinics in the main university hospital in Alexandria namely; geriatric, urology, diabetic, general medical, endocrine, hematology and gastrointestinal clinics. The working days of these clinics vary from one day per week to six days/week. The monthly attendance rate in these medical clinics ranged from 170-180 geriatric patients with different medical diagnosis.

Subjects: The study involved a convenience sample of 130 geriatric patients aged 60 years and above, males and females, able to communicate effectively, accept to participate in the study, have no urinary incontinence and suffer from nocturia. The number of the study subjects was calculated using the EPI info 0.7 program according to the following statistical parameters; population size 540 over three months, expected frequency $=50 \%$, acceptable error $=10 \%$, confidence coefficient $=99 \%$, the program revealed a minimum sample size of 127 geriatric patients and it was increased to the nearest round figure (130).

Tools: Two tools were used to gather the required data:

\section{Tool I: Socio-demographic and clinical data structured interview schedule of geriatric patients}

A: Socio-demographic data of the study older adults such as age, sex, marital status, level of education, occupation prior to retirement and monthly income.

B: Clinical data of the study older adults: This part was developed by the researcher through review of relevant literature to collect the following information from the study older adults: 
- Beginning of nocturia complaint, frequency of nocturia and associated symptoms.

- The presence of medical diseases affecting nocturia such as cerebrovascular diseases, cardiovascular diseases, prostatic hyperplasia, diabetes mellitus and obstructive sleep apnea.

- Medications that contribute to nocturia as antihypertensive, antipsychotic and stimulants.

- Fluid intake prior to sleep (including caffeine intake) and smoking.

Tool II: Sleep quality and Day Time Energy of geriatric patients with nocturia structured interview schedule

This tool was composed of two parts.

Part 1: Pittsburgh sleep quality index (PSQI).It was developed by Buysse and his colleagues (1988) (19). This tool was used in the current study to assess sleep quality of older adult patients with nocturia; it was adopted and modified by the researchers. As causes of sleep disturbance other than nocturia were excluded. The PSQI includes 9 questions; two pairs of the questions were pooled to measure two component of sleep quality as a result, the final questions were seven. Each question has a range of 0-2 points. In all cases a score of " 0 " indicates no difficulty, while a score of " 2 " indicates severe difficulty. The seven component scores were then added to produce one score, with a maximum of fourteen points; possible scores are classified in the following method:-

- Score 0-4: indicates good sleep quality.

- Score 5-9: indicates fairly good sleep quality.

- Score 10-14: indicates poor sleep quality.

Part 2: Day time energy of older adults with nocturia: This part of the tool was developed by the researchers after review of recent literature to assess daytime energy of older adult patients with nocturia and their ability to do the social, leisure and daily life activities in the last 2 weeks. This part included 8 questions; each question has a range of 0-2 points. The day time energy tool total score is 16 points and is categorized as follows:

- Score 0-5: indicates high day time energy.

- Score 6-10: indicates moderate day time energy.

- Score 11-16: indicates low day time energy.

\section{Method}

- Permission to carry out the study from the Faculty of Nursing, Alexandria University was obtained.

- Permission from head of the study setting was obtained, who were informed about the purpose of the study, the date and time of data collection.

- Socio-demographic and clinical data of the older adult patients structured interview schedule (tool I) was developed by the researcher based on in depth review of relevant literature.

- Part one of tool II (Pittsburgh Sleep Quality Index) was adopted, modified and translated into Arabic language by the researchers.

- Part two of tool II "Daytime Energy of Older Adult Patients with Nocturia" was developed by the researcher based on in depth review of related literature.

- Tool II was tested for content validity by 5 experts in the field of the gerontological nursing and the required modifications were done accordingly.

- Tool II was tested for reliability using Cronbach's alpha test and was applied 
on fifteen geriatric patients with nocturia at the Main University Hospital, ( $\mathrm{r}=0.95)$. Those patients were not included in the study subjects.

- A pilot study was done on fifteen older adults with nocturia who were selected from the study setting to assess the study tools for their applicability and clarity and those not included in the study sample. Accordingly the necessary modifications were done.

- Each older adult who fulfilled the inclusion criteria was interviewed individually by the researchers in the waiting area of the outpatient clinics while sitting comfortably, the researchers explained the purpose of the study in order to gain the geriatric patients' cooperation, then the necessary data was collected.

- The researcher used to attend the outpatient clinics from 8 Am three days per week.

- Time taken to complete the study tools during the interview with each patient ranged from 25-35 minutes depending on the level of co-operation of the geriatric patients and presence of quite environment.

- The data collection started from the beginning of November 2017 to the end of January 2018.

\section{Ethical considerations:}

Informed written consent from each older adult or witness consent from the caregiver was obtained to participate in this study after appropriate explanation of the study purpose. Anonymity and privacy of the study subjects and confidentiality of the collected data were maintained.

\section{Statistical Analysis}

The collected data were coded and analyzed using PC with the Statistical Package for Social Sciences (SPSS version
20) and tabulated frequency and percentages were calculated. Descriptive statistics as frequency, distribution, mean, and standard deviation were used to describe different characteristics. The Chi-square test, Fisher Exact Test and Monte Carlo test were used for testing relationship between categorical variables. The level of significance selected for this study was $\mathrm{p}$ value equal to or less than 0.05.Cronbach's alpha method is used to test the reliability.

\section{Results}

Table (1) illustrates the sociodemographic characteristics of the study older adults. The mean age of the study older adults was $66.5 \pm 5.1$ years, more than one half $(58.5 \%)$ were males, $70 \%$ were married. Nearly one half $(48.5 \%)$ of them were illiterate and had a skilled work (47.7\%). $70.8 \%$ of them reported their monthly income to be not enough.

According to table (2), all of the study older adults have nocturia with different frequencies, as nearly half $(45.4 \%)$ of them reported awakening twice to void, $33.8 \%$ three times and $20.8 \%$ four times or more. the table also, indicates that the duration of nocturia ranged from $0.16-23$ years with a mean of $5.58 \pm 4.87$ years. As reported by the study older adults; frequency of urination, burning sensation and urgency were the most common symptoms associated with nocturia $(42.3 \%, 38.5 \%$, and $30.8 \%$ respectively). Only $40 \%$ of the study geriatric patients reported seeking a medical help for treating nocturia.

Table (3) demonstrates the relationship between sleep quality (SQ) and level of daytime energy of the study older adults with nocturia. This table explicated that, the majority (90.3\%) of older adults with nocturia who had poor sleep quality demonstrated low level of day time energy. However, the majority of those who had good sleep quality reported high level of day time energy and the difference was statistically significant $\quad(\mathrm{FET}=105.909$, $\mathrm{P}=<0.000)$. 
As displayed in table (4), a positive statistical significant relation appears between frequency of nocturia and sleep quality (SQ) of the study older adults $(p=<0.000)$. It was noticed that the higher percentage $(55.6 \%)$ of those study older adults who awake four times or more at night to void had poor sleep quality than those who awake three $(38.6 \%)$ and two $(15.3 \%)$ times respectively. The table also, depicts a positive statistical significant relation between the duration of having nocturia and sleep quality of the study older adults $(\mathrm{P}=0.032)$

Table (5) shows the relationship between frequency and duration of having nocturia and level of day time energy of the study older adults. It was found that the study older adults who awake four times or more and those who awake three times at night to void had lowered level of day time energy $(59.3 \%)$ and $(54.5 \%)$ respectively and the difference was statistically significant $(\mathrm{p}=<0.000)$. Likewise, a statistically significant relation emerged between period of having nocturia and the level of day time energy of the study subjects $(\mathrm{P}=0.005)$.

\section{Discussion}

Nocturia is an annoying lower urinary tract symptom and is often viewed as an expected result of advanced age ${ }^{(3)}$. Despite this, the deleterious influence of nocturia has been overlooked until now, not only for its underreported prevalence ${ }^{(20,21)}$ but also for the subsequent physical and psychosocial problems $^{(22,23)}$. However, to our knowledge, there are limited studies measuring the frequency of nocturnal voids and its impact on sleep quality, physical vitality and ability to concentrate and produce in the clinical researches ${ }^{(24,25)}$. Consistent with previous research findings ${ }^{(21,26)}$, under reporting and under treatment of nocturia is confirmed by this research results as, sixty percent of the study geriatric patients didn't seek medical help (table 5). This finding may be related to several reasons. A primarily reason may be that some older adults regard nocturia as an expected outcome of aging and untreatable. Another reason may be that older adults especially female may be embarrassed to argue about this issue. Moreover, easily resuming of sleep after nocturnal voids and supplemental periods of sleep during the day may be responsible for perceiving nocturia as less bothering.

The findings of the current study reflected that, having nocturia as reported by the study subjects influences sleep quality as nearly one third of the study older adults reported to have poor SQ and around one half reported to have fairly good SQ (table $3)$. This may be caused by the frequently interrupted sleep by waking up at night to void and the ability of the older adults to fallback asleep may be problematic as the result of aging or the underlying environmental and psychological conditions. Consistently, recent studies done in Egypt $\left(2012\right.$ and 2014) ${ }^{(27,28)}$ reported that nocturia was significantly associated with disturbed sleep. Similar findings were declared through the studies done in China $(2016)^{(1)}$, in the USA (2009 and 2012) $)^{(18,29)}$ and in Japan $(2015)^{(25)}$ which corroborated significant affection of sleep quality correlated with nocturia. Other studies using different standard psychometric instruments such as Medical Outcomes Study Sleep Scale and Nordic Sleep Questionnaire also have shown associations of nocturia with poor sleep quality ${ }^{(30,31)}$. Arguably, some researchers have failed to identify nocturia as a primary source of disturbed sleep in older individuals, arguing that only few percents of older adults could identify the source for their awakening. As, they may awaken from one or more sleep disturbing factors other than nocturia then they perceive a need to void and decide to go to bathroom, Among these sleep disturbing factors are noise and light, medical conditions as osteoarthritis or specific sleep disorders such as sleep apnea. Accordingly, nocturia may be a consequence of sleep disturbance, rather than its source ${ }^{(18,32)}$. 
The geriatric patients in the current work demonstrated varied frequencies of nocturnal voids, as nearly one half of the them reported to wake up twice at night to void and more than one third of them reported to wake up three times followed by more than one fifth reported to wake up four times (table 2). Several reasons may explain this finding; first, the physiological changes that affect the urinary system, including the incongruity between amounts of urine created at night and the bladder's capacity to hold adequate urine volumes during sleep, and disturbed circadian nocturnal arginine vasopressin (AVP) secretion which results in a shift of the diurnal rhythm of urine construction toward increasing nighttime urine evacuation ${ }^{(9)}$, second, the presence of chronic diseases that affect the antidiuretic hormone secretion including endocrine disorder and heart failure. Third, the use of medications such as diuretics may be a reason for nocturnal voiding. This result is in accordance with the finding of several studies which concluded that from more than one third of older adults to almost two thirds reported to void two or more times per night $^{(3,5,33)}$. Additionally, the current study professed that, increased number of nocturnal voiding is associated with poorer sleep quality (Table 4). This may be owed to decreased sleep quality and quantity resulting from frequently interrupted sleep. This result stands in accordance with the findings of a study done in Egypt, Cairo $(2013)^{(34)}$, Taiwan $(2017)^{(35)}$ and in the USA $(2009)^{(9)}$ which reported that higher numbers of nocturnal voids associated with poorer sleep quality.

A significant affection of the level of day time energy due to poor sleep quality is reported by the majority of the studied older adults (table 3). This findings is in line with Asplund et al. $(2005)^{(36)}$ in Sweden who reported that sleep disturbance is the most significant consequence of nocturia with clear evidence of increased fatigue during the day and decreased energy and activity. On the contrary, Shao $(2016)^{(1)}$, found that negative outcome of nocturia on daytime dysfunction among older patients was not statistically significant explaining that, older adults may take additional napping time to restore energy during day. Furthermore, the current study revealed an increased affection of the level of day time energy as a result of increased frequency and duration of nocturia (table 5). Similarly, El Said et al in Egypt $(2013)^{(34)}$ and Kobelt et al. in Sweden $(2003)^{(22)}$ reported that interrupted sleep caused by excessive night time voiding lead to lower energy level. Likewise, AncoliIsrael et el. $(2005)^{(37)}$ in the USA found that unsatisfactory sleep can have imperative effects on daytime function by aggregating the need to nap, reducing mental abilities, reducing response time, undesirably affecting relationships with friends and family, and causing a general sense of unwell. Also, Vaughan et al. (2016) ${ }^{(38)}$ and Tsou $(2013)^{(39)}$ reported worse functional outcomes of sleep in older adults with nocturia. Undoubtly, we can conclude that, sleep disturbance act as a linkage between nocturia and day time fatigue.

\section{Conclusion}

Based on the findings of the present study it can be concluded that, presence of a positive statistical significant relation between sleep quality and day time energy of geriatric patients with nocturia. Also, Frequency and duration of nocturia was significantly associated with sleep quality and day time energy. Moreover, elders with nocturia have either fairly good or poor SQ and poor level of day time energy.

\section{Recommendations}

- Health care providers should regularly assess those patients at-risk for nocturia and use it as a screen test for predicting other serious medical disorders

- Preparation of educational booklets by the gerontological nurse to acquaint patient with the necessary information about nocturia, its consequences and the importance of seeking medical help and to be distributed at different outpatient healthcare settings .

- The gerontological nurses should participate in raising awareness of the public about causes, consequences, and management of nocturia in older adults through mass media programs. 
Table (1): Distribution of the study older adults according to their socio-demographic characteristics

\begin{tabular}{|c|c|c|}
\hline Socio-demographic characteristics & Frequency $(n=130)$ & Percent (\%) \\
\hline $\begin{array}{l}\text { Age (in years) } \\
60- \\
65- \\
70- \\
75 \text { and more } \\
\end{array}$ & $\begin{array}{l}51 \\
40 \\
25 \\
14\end{array}$ & $\begin{array}{l}39.2 \\
30.8 \\
19.2 \\
10.8\end{array}$ \\
\hline Mean \pm SD & 66.5 & \\
\hline $\begin{array}{l}\text { Sex } \\
\text { Male } \\
\text { Female } \\
\end{array}$ & $\begin{array}{l}76 \\
54 \\
\end{array}$ & $\begin{array}{l}58.5 \\
41.5 \\
\end{array}$ \\
\hline $\begin{array}{l}\text { Marital status } \\
\text { Married } \\
\text { Widow } \\
\text { Divorced } \\
\end{array}$ & $\begin{array}{c}91 \\
37 \\
2 \\
\end{array}$ & $\begin{array}{c}70.0 \\
28.5 \\
1.5\end{array}$ \\
\hline $\begin{array}{l}\text { Level of education } \\
\text { Illiterate } \\
\text { basic education } \\
\text { Read and write } \\
\text { Secondary education } \\
\text { University education and above }\end{array}$ & $\begin{array}{c}63 \\
28 \\
18 \\
13 \\
8\end{array}$ & $\begin{array}{c}48.5 \\
21.5 \\
13.8 \\
10.0 \\
6.2\end{array}$ \\
\hline $\begin{array}{l}\text { Occupation before retirement } \\
\text { Skilled work } \\
\text { No occupation } \\
\text { Employee }\end{array}$ & $\begin{array}{l}62 \\
45 \\
23\end{array}$ & $\begin{array}{l}47.7 \\
34.6 \\
17.7\end{array}$ \\
\hline $\begin{array}{l}\text { Monthly income } \\
\text { Not Enough } \\
\text { Enough } \\
\end{array}$ & $\begin{array}{l}92 \\
38 \\
\end{array}$ & $\begin{array}{r}70.8 \\
29.2 \\
\end{array}$ \\
\hline $\begin{array}{l}\text { Source of income } \\
\text { Pension } \\
\text { Sons and daughters } \\
\text { Current work } \\
\text { Financial assistance }\end{array}$ & $\begin{array}{c}82 \\
27 \\
17 \\
4\end{array}$ & $\begin{array}{c}63.1 \\
20.8 \\
13.1 \\
3.1\end{array}$ \\
\hline $\begin{array}{l}\text { Living condition } \\
\text { With his / her partner in marriage house } \\
\text { With his son in marriage house } \\
\text { Alone in marriage house } \\
\text { With his son in his sons house } \\
\text { With relatives }\end{array}$ & $\begin{array}{c}93 \\
28 \\
4 \\
4 \\
1\end{array}$ & $\begin{array}{l}71.5 \\
21.5 \\
3.1 \\
3.1 \\
0.8\end{array}$ \\
\hline
\end{tabular}


Table (2): Distribution of the study older adults according to nocturia self- reported characteristics

\begin{tabular}{|c|c|c|}
\hline Duration of nocturia (in years) & Frequency $(n=130)$ & Percent (\%) \\
\hline$<5$ & 69 & 53.1 \\
\hline $5<10$ & 32 & 24.6 \\
\hline $10<15$ & 19 & 14.6 \\
\hline \multirow{3}{*}{15 or more } & 10 & 7.7 \\
\hline & Min-Max & Mean \pm SD \\
\hline & $0.16-23$ & $5.58 \pm 4.87$ \\
\hline \multirow{4}{*}{$\begin{array}{l}\text { Frequency of nocturia } \\
\text { Two times } \\
\text { Three times } \\
\text { Four times or more }\end{array}$} & Frequency $(n=130)$ & Percent (\%) \\
\hline & 59 & 45.4 \\
\hline & 44 & 33.8 \\
\hline & 27 & 20.8 \\
\hline \multirow{2}{*}{$\begin{array}{l}\text { Associated symptoms with nocturia } \\
\text { None }\end{array}$} & Frequency $(n=130)$ & Percent (\%) \\
\hline & 23 & 17.7 \\
\hline Frequency of urination & 55 & 42.3 \\
\hline Burning sensation on urination & 50 & 38.5 \\
\hline Urgency & 40 & 30.8 \\
\hline Incomplete bladder emptying & 22 & 16.9 \\
\hline Weak urine stream & 20 & 15.4 \\
\hline Hesitancy & 14 & 10.8 \\
\hline Post void dribbling & 4 & 3.1 \\
\hline Hematuria & 2 & 1.5 \\
\hline \multirow{3}{*}{$\begin{array}{l}\text { Seeking medical help for nocturia } \\
\text { No } \\
\text { Yes }\end{array}$} & Frequency $(n=130)$ & Percent (\%) \\
\hline & 78 & 60.0 \\
\hline & 52 & 40.0 \\
\hline
\end{tabular}

Table (3): Frequency distribution and relationship between sleep quality (SQ) and level of daytime energy of the study older adults

\begin{tabular}{|c|c|c|c|c|c|c|c|c|c|c|}
\hline \multirow{3}{*}{ Sleep Quality } & \multirow{2}{*}{\multicolumn{2}{|c|}{$\begin{array}{c}\text { Total Sleep } \\
\text { Quality }\end{array}$}} & \multicolumn{6}{|c|}{ Level of daytime energy } & \multicolumn{2}{|c|}{$\begin{array}{c}\text { Test of } \\
\text { significance }\end{array}$} \\
\hline & & & \multicolumn{2}{|c|}{$\begin{array}{c}\text { Low level of } \\
\text { daytime energy }\end{array}$} & \multicolumn{2}{|c|}{$\begin{array}{c}\text { Moderate level } \\
\text { of daytime } \\
\text { energy }\end{array}$} & \multicolumn{2}{|c|}{$\begin{array}{l}\text { High level of } \\
\text { daytime energy }\end{array}$} & FET & $P$ value \\
\hline & No & $\%$ & NO & $\%$ & NO & $\%$ & NO & $\%$ & \multirow{4}{*}{105.909} & \multirow{4}{*}{$0.000^{*}$} \\
\hline GOOD SQ & 28 & 21.5 & 0 & 0.0 & 4 & 14 & 24 & 86 & & \\
\hline Fairly Good SQ & 61 & 46.9 & 14 & 23 & 35 & 57.4 & 12 & 19.6 & & \\
\hline Poor SQ & 41 & 31.5 & 37 & 90.3 & 4 & 9.7 & 0 & 0.0 & & \\
\hline \multicolumn{3}{|c|}{ Total level of daytime energy } & 51 & 39.2 & 43 & 33.1 & 36 & 27.7 & & \\
\hline
\end{tabular}

FET: Fisher exact test

$P$ value is significant $<0.05$ 
Table (4): Relationship between frequency and duration of nocturia and sleep quality (SQ) of the study older adults

\begin{tabular}{|c|c|c|c|c|c|c|c|c|}
\hline \multirow{4}{*}{$\begin{array}{l}\text { Frequency and duration of } \\
\text { nocturia }\end{array}$} & \multicolumn{6}{|c|}{ Sleep quality(SQ) } & \multicolumn{2}{|c|}{ Test of significance } \\
\hline & \multicolumn{2}{|c|}{ Good SQ } & \multicolumn{2}{|c|}{$\begin{array}{l}\text { Fairly Good } \\
\text { SQ }\end{array}$} & \multicolumn{2}{|c|}{ Poor SQ } & FET & $P$ values \\
\hline & NO & $\%$ & NO & $\%$ & NO & $\%$ & \multirow{4}{*}{26.398} & \multirow{4}{*}{$0.000 *$} \\
\hline & 23 & 39.0 & 27 & 45.8 & 9 & 15.3 & & \\
\hline Three times & 4 & 9.1 & 23 & 52.3 & 17 & 38.6 & & \\
\hline Four times or more & 1 & 3.7 & 11 & 40.7 & 15 & 55.6 & & \\
\hline $\begin{array}{l}\text { Duration of nocturia (in years) } \\
<5\end{array}$ & 18 & 26.1 & 35 & 50.7 & 16 & 23.2 & \multirow{4}{*}{8.651} & \multirow{4}{*}{$0.032 *$} \\
\hline $5<10$ & 7 & 21.9 & 11 & 34.4 & 14 & 43.8 & & \\
\hline $10<15$ & 3 & 15.8 & 10 & 52.6 & 6 & 31.6 & & \\
\hline 15 and more & 0 & 0.0 & 5 & 50.0 & 5 & 50.0 & & \\
\hline
\end{tabular}

FET: Fisher exact test

$P$ value is significant $<0.05$

Table (5): Relationship between frequency and duration of nocturia and level of daytime energy of the study older adults

\begin{tabular}{|c|c|c|c|c|c|c|c|c|}
\hline \multirow{2}{*}{$\begin{array}{l}\text { Frequency and duration of } \\
\text { nocturia }\end{array}$} & \multicolumn{6}{|c|}{ Level of daytime energy } & \multicolumn{2}{|c|}{ Test of significance } \\
\hline & \multicolumn{2}{|c|}{ Low } & \multicolumn{2}{|c|}{ Moderate } & \multicolumn{2}{|c|}{ High } & FET & P values \\
\hline Frequency of nocturia & NO & $\%$ & NO & $\%$ & NO & $\%$ & \multirow{4}{*}{23.692} & \multirow{4}{*}{$<0.000$} \\
\hline Two times & 11 & 18.6 & 22 & 37.3 & 26 & 44.1 & & \\
\hline Three times & 24 & 54.5 & 12 & 27.3 & 8 & 18.2 & & \\
\hline Four times or more & 16 & 59.3 & 9 & 33.3 & 2 & 7.4 & & \\
\hline $\begin{array}{l}\text { Duration of nocturia } \\
\text { (in years) } \\
<5\end{array}$ & 19 & 27.5 & 27 & 39.1 & 23 & 33.3 & \multirow{4}{*}{12.014} & \multirow{4}{*}{0.005} \\
\hline $5<10$ & 14 & 43.8 & 11 & 34.4 & 7 & 21.9 & & \\
\hline $10<15$ & 11 & 57.9 & 3 & 15.8 & 5 & 26.3 & & \\
\hline 15 and more & 7 & 70.0 & 2 & 20.0 & 1 & 10.0 & & \\
\hline
\end{tabular}

FET: Fisher exact test

$P$ value is significant $<0.05$ 


\section{References}

1. Shao H, Wu C, Hsu H, Chang S, Wang H, Chuang H, Tam Y.The effect of nocturia on sleep quality and daytime function in patients with lower urinary tract symptoms: a cross-sectional study. Clinical Interventions in Aging 2016; 11:879-85.

2. Ancoli-Israel S, Bliwise DL, Norgaard JP. The effect of nocturia on sleep. Sleep Med Rev. 2011; 15(2):91-97.

3. Bosch JL, Weiss JP. The prevalence and causes of nocturia. Journal of Urology 2010; 184(2):440-6.

4. Burgio KL, Johnson TM 2nd, Goode PS, Markland AD, Richter HE, Roth DL, Sawyer P, Allman RM. Prevalence and Correlates of Nocturia in CommunityDwelling Older Adults. Journal of American Geriatric Society 2010; 58(5):861-6.

5. Abdel Rahman TT, El Gaafary MM. Nocturia among elderly men living in a rural area in Egypt, and its impact on sleep quality and health-related quality of life. Geriatric Gerontology International 2014; 14(3):613-9.

6. van Kerrebroeck P, Abrams P, Chaikin D, et al; Standardisation Subcommittee of the International Continence Society. The standardisation of terminology in nocturia: report from the Standardisation Subcommittee of the International Continence Society. Neurourol Urodyn. 2002;21(2):179-183.

7. Meiner SE. Gerontological Nursing.5th ed., USA: Mosby CO., 2015; 541-2.

8. Ham RJ, Sloane PD. Primary Care Geriatrics A case-Based Approach.3rd ed., USA: Mosby Co., 1997; 20-4.

9. Boongird S, Shah N, Nolin TD, Unruh ML. Nocturia and Aging: Diagnosis and Treatment Advanced Chronic Kidney Disease. The National Kidney Foundation 2010; 17(4):27-40.

10. Timby BK. Fundamental Nursing Skills and Concepts.9th ed., China: Wolter Kluwer CO., 2009; 707-17.
11. Weiss JP, Blaivas JG, Bliwise DL et al. The evaluation and treatment of nocturia: a consensus statement. BJU Int. 2011; 108(1):6-21.

12. Osman NI, Chapple CR. Focus on nocturia in the elderly Aging Health 2013 9(4): 389402. https://doi.org/10.2217/ahe.13.22

13. Yoo SS, Shim BS, Lee DH, Lee HW, Yoon H. Correlation between Nocturia and Sleep: A Questionnaire Based Analysis. Korean J Urol 2010; 51:757-762

14. Vaughan CP, Brown CJ, Goode PS, Burgio KL, Allman RM, Johnson TM 2nd. The association of nocturia with incident falls in an elderly community-dwelling cohort. Int. J. Clin. Pract. 2010; 64(5),577-583.

15. Johnson TV, Abbasi A, Ehrlich SS, Kleris RS, Raison CL, Master VA. Nocturia associated with depressive symptoms. Urology 2011;77(1),183-186.

16. Kupelian V, Fitzgerald MP, Kaplan SA, Norgaard JP, Chiu GR, Rosen RC. Association of nocturia and mortality: results from the Third National Health and Nutrition Examination Survey. J. Urol 2011; 185(2):571-77.

17. Kim SC, Lee SY. Men's lower urinary tract symptoms are also mental and physical sufferings for their spouses. J. Korean Med. Sci. 2009; 24(2):320-325.

18. Bliwise DL, Foley DJ, Vitiello MV, Ansari FP, Ancoli-Israel S, Walsh JK. Nocturia and disturbed sleep in the elderly. Sleep Med.2009; 10(5): 540-48.

19. Buysse DJ, Reynolds CF 3rd, Monk TH, Berman SR, Kupfer DJ. The Pittsburgh Sleep Quality Index: a new instrument for psychiatric practice and research. Psychiatry Research 1989; 28(2): 193-213.

20. Coyne KS, Zhou Z, Bhattacharyya SK, Thompson CL, Dhawan R, Versi E. The prevalence of nocturia and its effect on health-related quality of life and sleep in a community sample in the USA. BJU International 2003; 92(9):948-54.

21. MacDiarmid S, Rosenberg M. Overactive bladder in women: symptom impact and 
treatment expectations. Current Medical Research and Opinion 2005; 21(9):141321.

22. Kobelt G, Borgstrom F, Mattiasson A. Productivity, vitality and utility in a group of healthy professionally active individuals with nocturia. BJU International journal 2003; 91(3):190-5.

23. Hetta J. The impact of sleep deprivation caused by nocturia. BJU International 1999; 84 (Suppl 1): 27-8.

24. Chartier-Kastler E, Tubaro A. The Measurement of Nocturia and Its Impact on Quality of Sleep and Quality of Life in LUTS/BPH. European Urology Supplements 2006; 5(1):3-11.

25. Obayashi K, Saeki K, Kurumatani N. Quantitative association between nocturnal voiding frequency and objective sleep quality in the general elderly population: the HEIJO-KYO cohort. Sleep Medicine 2015; 16(5):577-82.

26. Chen FY, Dai YT, Liu CK, Yu HJ, Liu CY, Chen THH. Perception of nocturia and medical consulting behavior among community-dwelling women. International Urogynecological Journal 2007; 18(4):4316.

27. Baker IM, Abd Elaziz K, Abou El Ezz N, Fahim HI. Insomnia in Institutionalized older people in Cairo, Egypt: prevalence and risk factors associated. European geriatric medicine 2012; 3(2):92-6.

28. Abd Allah ES, Abdel-Aziz HR, Abo ElSeoud AR. Insomnia: Prevalence, risk factors, and its effect on quality of life among elderly in Zagazig City, Egypt. Journal of Nursing Education and Practice 2014; 4(8):52.

29. Parthasarathy S, Fitzgerald M, Goodwin JL, Unruh M, Guerra S, Quan SF. Nocturia, sleep- disordered breathing, and cardiovascular morbidity in a communitybased cohort. PLoS One Journal. 2012; 7(2): e30969.

30. Lau DT, Morlock RJ, Hill CD. Psychometric evaluation of the medical outcomes study-sleep scale in persons with overactive bladder. Clinical Therapeutics 2006; 28 (12):2119-32.
31. Drake NL, Flynn MK, Romero AA, Weidner AC, Amundsen CL. Nocturnal polyuria in women with overactive bladder symptoms and nocturia. American Journal of Obstetrics and Gynecology 2005; 192(5):1682-6.

32. Pressman MR, Figueroa WG, KendrickMohamed J, Greenspon LW, Peterson DD. Nocturia. A rarely recognized symptom of sleep apnea and other occult sleep disorders. Arch Intern Med Mar 11; 1996 156(5):545-50.

33. Wang L, Liu B, Huang S, Wu Q, Wu D. Prevalence and risk factors of nocturia and quality of life of nocturia subjects from Shanghai. Acta Medica Mediterranean 2014; 30: 1103.

34. El Said SMS, Abd El Rahman T, Mortagy AK, Mansour MW. Nocturia: Impact on quality of life in an Egyptian adult population. Advances in Aging Research 2013; 2(4):160-5.

35. Chang CJ, Pei D, Wu CC, Palmer MH, Su CC, Kuo SF, Liao YM. Correlates of Nocturia and Relationships of Nocturia with Sleep Quality and Glycemic Control in Women with Type 2 Diabetes. Journal of nursing scholarship 2017; 49(4):400-10.

36. Asplund R. Nocturia: consequences for sleep and daytime activities and associated risks. European Urology Supplements 2005; 3(6):24-32.

37. Ancoli-Israel S, Cooke JR. Prevalence and comorbidity of insomnia and effect on functioning in elderly populations. Journal of the American Geriatric Society. 2005; 53(7):264-71.

38. Vaughan CP, Fung CH, Huang AJ, Johnson 2nd TM, Markland AD. Differences in the Association of Nocturia and Functional Outcomes of Sleep by Age and Gender: A Cross-sectional, Population-based Study 2016; 38(11):2386-93.

39. Tsou MT. Prevalence and risk factors for insomnia in community-dweling elderly in northern Taiwan. Journal of Clinical Gerontology and Geriatrics.2013; 4(3):759. 